\title{
Study Of Relationship Between Attitude And Problems Experienced By Mothers Of Children With Cerebral Palsy
}

\author{
Shaista Naz \\ Department of Education \\ Sindh Madressatul Islam University \\ Nasir Sulman \\ Department of Special Education \\ University of Karachi
}

\begin{abstract}
The present research work was carried out to study the attitudes and problems experienced by mothers of children with cerebral palsy. To achieve this broad objective, scales for the attitudes of mothers and problems experienced by them were developed. It was found that a mother's attitudes to cerebral palsy were determined by the severity of the child's disability. The severe the disability, the less favourable were the mother's attitudes. Mothers having better attitudes experienced less problems compared to those who had poor and unfavourable attitudes. The degree of cerebral palsy in the child and its I.Q. were seen to influence their problem score. The age, sex, birth order of the child, age of mother and the type of family did not affect the mother's problem score. However, parental education, occupation, habitat and family income were found to be directly related to their problems.

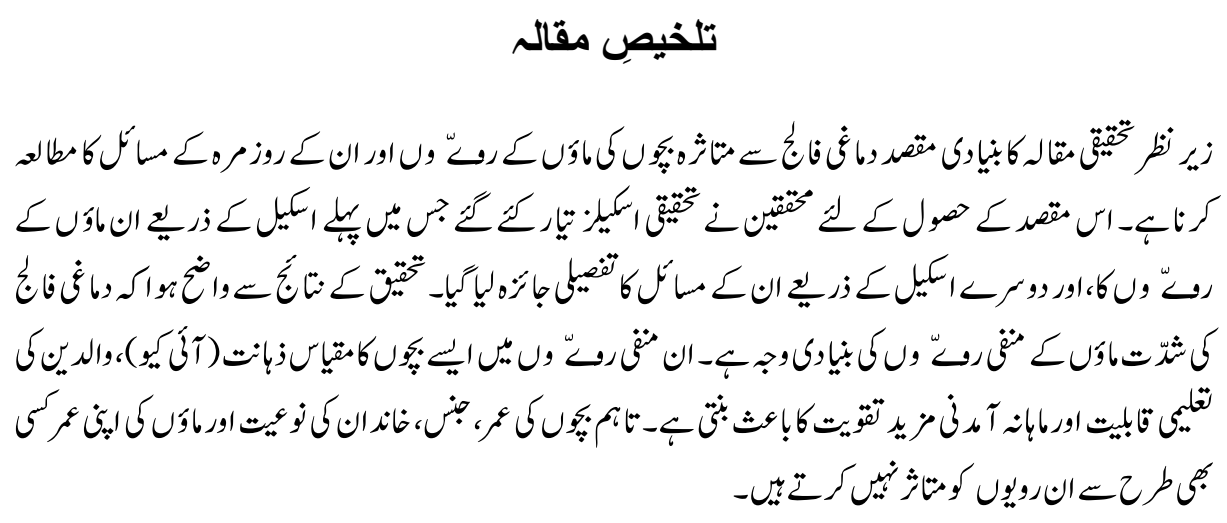

Key Words: Cerebral palsy, Attitude, Maternal problems, Perception, Rating Scale

\section{Introduction}

It is generally believed that a child with cerebral palsy (CP) is not only a tragic human figure in his own self but brings profound and endless suffering to his parents (Hummenlinck \& Pollock, 2006). Britner, Morog, Pianta, \& Marvin (2003) reported that the arrival of such a child is really a shock and many parents find it very difficult to come to terms with the situation when 
they come to know about its implications. The moment the parents learn that their child will not be able to lead a normal life and may have to remain functionally dependent in activities of daily life, the clouds of grief, shock, gloom and frustration hover over their heads and cloud further rational thinking about the matter (Florian \& Findler, 2001).

Pain (1999) identified many questions which are arising in the minds of parents about the future of the child. For their satisfaction they take the child to different specialists for the confirmation and reconfirmation of the diagnosis and prognosis. Knowledge regarding the irreversibility of the condition results in anxiety and may some times lead to marital discord. Pianta, Marvin, Britner, \& Borowitz (1996) reported that the mother is usually blamed for giving birth to a handicapped child. Her tensions are likely to be greater because, in spite of being blamed for what she is not responsible, she has to look after the child day and night. In the process she has to subjugate her own desires and ambitions. They further pointed out several behaviors like a sense of guilt, self-doubt and insecurity which are reflected on their personalities. Such psychological tensions may hamper optimal upbringing and care of the handicapped child.

In many urban and rural families, parents still believe that birth of a child with cerebral palsy is a curse on the family for some sins committed by the family members in their past life (Raina, O'Donnell, Rosenbaum, Brehaut, Walter, Russell, 2005; Seligman, 1983). These children are considered to be a cause of humiliation and a social stigma for their families (Wishart et al, 1981; Sensky, 1982; Seligman, 1983; Verma, 1989). In some cases, normal children are not allowed to come close to the handicapped child. Parents of handicapped children are not invited to social get-togethers. When faced with such humiliations on repeated occasions, the parents, especially the mothers, slowly withdraw from social activities. The burden of isolation is added to the feeling of shame. All these hamper the mother's capacity to manage the child and her problems.

Many rural, illiterate people still feel that a CP child is a slur on the family name (Morris, 2009). Neighbours and relatives often pass hurtful comments, knowingly or unknowingly, depending upon their cultural and educational background. Such encounters make the parents always conscious about the handicap of the child (King, Teplicky, King \& Rosenbaum, 2004; Verma, 1989). The fact that even in the modern and scientific age, such attitudes are still prevalent in our society, may be a matter of some surprise, but is a harsh truth one encounters amongst the illiterate and semiliterate populations both in urban and rural areas of our country. The effects of these negative attitudes are that children are hidden away from the eyes of the neighbours and are thus denied appropriate care in the early stages. Ignorance about the cause of $\mathrm{CP}$ in these groups is understandable, but it is noteworthy that the urban well-educated members of our society are not well informed about the causation of cerebral palsy.

Arrival of a CP child in a family has a great impact on the whole family as pointed out earlier. However, the nature of problems and the reactions/ responses that arouse in the family has not been fully explored. The incapacity of the child may develop a feeling of sympathy for the "poor helpless" child. This may lead to two consequences. The mothers may involve themselves so much in the care of the $\mathrm{CP}$ child that the care of their healthy children may 
suffer. Secondly, the CP child may become a passive recipient of care, whereas active participation would be more beneficial. The reactions which arise in such a family may lead to problems which would be an appropriate subject for study.

With the modern holistic approach in the care of disabled subjects, each individual is looked up as the focal point. Understanding of psychological, sociological, and emotional background of the whole family is an essential component of the total care programme. Admission of such children in the residential institutions is not expected to solve the problems of such families. Home-care programme is the correct way to care for handicapped children, so that the parents can be trained to participate in the care of their child and the child gets an opportunity to grow up with the love and understanding which only close family members can provide.

Research work on the handicapped has so far focused mainly on the impact of the handicap on the affected subject. The problems that may arise within the family, the intra-family dynamics, the parent-child interactions and the study of parental attitudes towards cerebral palsy have not been studied in depth. As described earlier, the attitudes of society towards $\mathrm{CP}$ are believed to be the prime reason that cause tensions in the family life and result in the neglect of the CP child. Social demographic factors such as parental education, income, social support, urban rural habitat and age of the mother are other factors known to be important in influencing attitudes. Since attitudes influence the management of any conditions, it appeared desirable to evolve an objective measure of parental attitude to CP. The scales described in western literature cannot be used under the local conditions.

The problems encountered by the mother of a CP child, is a significant area for which virtually no objective method of measurement could be traced. Therefore, development and standardization of such a tool was considered another useful step in order to facilitate the understanding of family dynamics. It would also be worthwhile to know as to whether the child's characteristics like age, sex, degree of spasticity are related to the attitudes of the mother.

\section{Methodology}

\section{Sample}

Mothers having a child with cerebral palsy in the age range of 2 to 12 years visiting the Department of Neurology, Liaquat National Hospital, Karachi were included in the study. A total of 120 mothers who were qualified according to following two criteria:

i) whose child had been found to be cerebral palsy as confirmed by a qualified pediatrician or neurologist of the department,

ii) The family should be residing in Karachi city only.

\section{Instrument}

For the purpose of data collection, following two scales were prepared by the investigator. 


\section{A) Mothers' Problem Rating Scale (MPRS)}

It was considered essential to include important problems experienced by the mothers. Items on problems relating to the following areas of activity were included for study.

(a) Personal and psychological problems

(b) Social and Family problems.

(c) Economic problems

The significant sources were:

(a) Detailed interview with the mother of $\mathrm{CP}$ child

(b) Discussion and opinion of the experts

(c) Published literature.

The number of items in each of the three areas delineated above is given in the following table.

Table 1

Items and areas selected initially for rating scale for problems experienced by mothers of children with cerebral palsy

\begin{tabular}{|l|c|}
\hline \multicolumn{1}{|c|}{ Mother's perception of: } & No. of items \\
\hline a) Personal and psychological problems & 18 \\
\hline b) Social and family problems & 43 \\
\hline c) Financial problems & 07 \\
\hline Total & $\mathbf{6 8}$ \\
\hline
\end{tabular}

The items chosen were written in simple Urdu. Special care was taken to ensure that statements are applicable to mothers of both male and female children, and are easily understood by illiterate as well as literate mothers, irrespective of their socio-economic status. Suggestions of experts were incorporated and language of the items was modified wherever necessary. Each statement was read out to semi-illiterate or literate subjects and they were asked to explain in their own words as to what they had understood from the statement. After a study of mothers' responses and discussion with the experts, twenty three items were deleted. The reasons for deletion of items were ambiguity, duplication, rejection, rearrangement and amalgamation with other statements. Out of 68 items, 45 were left for pretesting.

A pre-test of the scale was carried out on 25 subjects. Mothers of different age groups, socio-economic status and different educational level having a CP child in the family were interviewed. It was ensured that mothers with children of different degrees of spasticity (i.e. mild, moderate and severe) were included in the pre-testing stage. The responses were evaluated and 31 items were retained on the basis of endorsement percentage of each item. 
Each statement was rated on a 3 point scale i.e. 'very true, 'somewhat true', 'not at all true'. For a positive statement the 'very true' response was given a score of 3, 'somewhat true' a score of 2 and not at all true' a score of 1 . For negative statements the scoring system was reversed; the 'not at all response' was given a score of 3, 'somewhat true' a score of 2 and 'very true response' a score of 1 . It requires 10 to 15 minutes for its administration and has finally included 14 items through which problems experienced by mother were assessed. The data on 120 mothers from the study group was collected.

\section{B) Scale of Mothers' Attitude towards Cerebral Palsy (SMCP)}

It was considered essential to include important areas of cerebral palsy where attitudes could differ. Items on attitudes from the following areas were selected:

(a) Mother's perception of expectations and prospects of a $\mathrm{CP}$ child

(b) Perception of the needs of the child

(c) Perception of schooling and play activity

(d) Perception of social and personal image on account of presence of a CP child

The number of items in each of the four areas delineated above is given in Table 2.

Table 2

Items and areas selected initially for the attitude scale

\begin{tabular}{|l|c|}
\hline \multicolumn{1}{|c|}{ Mother's perception of: } & No. of items \\
\hline a) Expectation and prospects of the child & 17 \\
\hline b) Needs of the child & 9 \\
\hline c) Schooling and play activity & 13 \\
\hline d) Perception of social and personal image & 45 \\
\hline Total No. of items & 84 \\
\hline
\end{tabular}

A pre-test of the scale was carried out on 25 subjects. Mothers with different age groups, socio-economic status and different educational level having a spastic child in the family were interviewed. It was ensured that mothers with children of different degrees of spasticity (i.e. mild, moderate and severe) were included in the pre-testing stage. The responses were evaluated and 41 items were retained on the basis of endorsement percentage of each item.

A five point (Likert, 1932) type rating scale procedure, in vogue in most of the attitude scales, was accepted. For favourable statement, the 'strongly agreed' response was given a score of 5, 'the agreed' response a score of 4, the undecided response' a score of 3 , and 'disagreed response' a score of 2, and 'strongly disagreed' response a score of 1. For unfavourable statements, the scoring system was reversed with 'strongly disagreed' response being given a score of 5 and 'strongly agreed' response a score of 1 . 
It followed all methods i.e. editing, try-out, pre-testing and final standardization which are used for the construction of a scale. Items found to be discriminatory between low scorer and high scorer groups were retained. This final 20 -item scale was thus ready for use as an instrument to achieve the other aims of the study.

\section{Procedure}

A list of names and addresses of all those children diagnosed as cerebral palsed at Department of Neurology, Liaquat National Hospital, Karachi during the year 2011-13 was prepared. There were 366 such cases of 2-12 years of age in which 120 cases had given their addresses which were located in different districts of Karachi region.

The following criteria were used for inclusion of subjects:

(a) Age of the CP child is between 2-12 years.

(b) Parents are residing in Karachi region.

(c) Mother is alive and willing to cooperate.

(d) Child had a clear diagnosis of cerebral palsy without any other chronic illness.

The mothers of the CP children who had visited the centre for the last six months were approached through a follow-up contact, requesting them to come along with the child for an interview on special days and time. The mothers who did not report were sent subsequent reminder letters and/or telephonic calls. Whenever no response was received on two reminders, the researcher personally visited their home and requested the mother to bring the child to the hospital. All the mothers, who brought their children in response to the letter or to the visit, were included in the study.

On every Saturday, a special clinic is held at the Department of Neurology, Liaquat National Hospital, Karachi. All types of handicapped children are seen and examined on that day. The clinician examined the child thoroughly noting down milestones, taking down the history, systematic examination of motor function, hearing, vision, reflexes and information on daily functions such as toilet needs, feeding, dressing etc on a specially prepared proforma where the type of cerebral palsy and its degree was also mentioned. After the clinical examination the researcher took up those cases which were diagnosed as cerebral palsy. The mothers of CP children who met the inclusion criteria enumerated above were requested to participate in the study. They were told about the objectives of the study. These mothers were interviewed at their convenience on the same day or on their next visit to the hospital. 


\section{Findings}

Table 3 shows demographic characteristics of mothers in the study group. Fifty six percent $(56 \%)$ mothers were less than 30 years of age. Sixty one percent $(61 \%)$ had acquired education upto matriculation level. Fifty eight percent belonged to nuclear families and 42 percent belonged to joint families. Only 16 percent families had income exceeding Rs. 30,000/- per month.

Table 3

Socio-demographic characteristics of mothers in study group

\begin{tabular}{|c|c|c|}
\hline Demographic characteristics & Study group $(\mathrm{N}=120)$ & Percent \\
\hline $\begin{array}{l}\text { 1. Age of mother (in yrs) } \\
21-25 \\
26-30 \\
31-35 \\
36 \text { and more } \\
\text { Mean } \\
\text { Standard Deviation } \\
\text { Range }\end{array}$ & $\begin{array}{c}24 \\
43 \\
35 \\
18 \\
30.18 \\
5.20 \\
21-45 \\
\end{array}$ & $\begin{array}{l}20.00 \\
35.83 \\
29.17 \\
15.00\end{array}$ \\
\hline $\begin{array}{l}\text { 2. Education of mother } \\
\text { Upto middle } \\
\text { Matriculation } \\
\text { Intermediate - Graduation } \\
\text { Above graduation } \\
\text { Years of schooling (Mean) } \\
\text { Standard Deviation } \\
\text { Range }\end{array}$ & $\begin{array}{c}40 \\
33 \\
33 \\
14 \\
9.40 \\
4.98 \\
0-16 \\
\end{array}$ & $\begin{array}{l}33.33 \\
27.50 \\
27.50 \\
11.66\end{array}$ \\
\hline $\begin{array}{l}\text { 3. Type of family } \\
\text { Nuclear } \\
\text { Joint } \\
\end{array}$ & $\begin{array}{l}70 \\
50 \\
\end{array}$ & $\begin{array}{l}58.33 \\
41.67\end{array}$ \\
\hline $\begin{array}{l}\text { 4. Family income (in RS) } \\
\text { Upto } 10,000 /= \\
10,000-20,000 /= \\
20,000-30,000 /= \\
30,001 \text { and above } \\
\text { Mean } \\
\text { Standard Deviation } \\
\text { Range }\end{array}$ & $\begin{array}{c}38 \\
48 \\
15 \\
19 \\
18,500 /= \\
11,290 /= \\
4,000-40,000 /=\end{array}$ & \\
\hline
\end{tabular}

Table 4 below indicates the relationship between mothers' problems and their attitude scores. 
Study of Relationship between Attitude and Problems Experienced by Mothers of Children with Cerebral Palsy

Table 4

Relationship between mother's problems score and attitude score

\begin{tabular}{|l|c|c|c|}
\hline Attitude Score & \multirow{2}{*}{$\begin{array}{c}\text { No. of } \\
\text { Mothers }\end{array}$} & \multicolumn{2}{|c|}{ Problems Score } \\
\cline { 3 - 4 } & 30 & 27.23 & 3.95 \\
\hline Less favourable (50 and less) & 44 & 29.54 & 2.63 \\
\hline Favourable (51 - 60) & 46 & 34.37 & 3.12 \\
\hline More favourable (61 and above) & \multicolumn{3}{|c|}{$\mathbf{r = 0 . 7 0 7 ; ~} \mathbf{p = 0 . 0 1}$} \\
\hline
\end{tabular}

There was significant correlation between problems and attitudes score $(r=0.707)$. Better the attitudes, lesser the mother's problems and vice versa. It was observed that mothers, who had poor attitudes, enumerated more problems. This is evident from the high significant correlation between attitudes and mother's problems rating scores, thus indicating that health professionals should also pay attention to the problems of mothers and not only to the handicapped children alone for holistic rehabilitation. This fact has also been studied by Rosenberg (1977), Channabasvanna et a1 (1985) and Bhatti et. a1. (1985). When a CP child is living within a family, unless the problems of providers of care to the child are not attended to, the care of the child is likely to be compounded. On the other hand, if mother's problems are taken care of, she would have time to look after the child, otherwise she would be worrying about her own problems finding no time to take care of the child who requires constant help in more simple activities of daily living.

Table 5

Relationship between mother's problems score and degree of cerebral palsy

\begin{tabular}{|l|c|c|c|}
\hline \multirow{2}{*}{ Degree of Cerebral Palsy } & No. of & \multicolumn{2}{|c|}{ Problems Score } \\
\cline { 3 - 4 } & Mothers & Mean & Standard Deviation \\
\hline Mild (0-13) & 38 & 34.81 & 3.09 \\
\hline Moderate (14-41) & 53 & 29.83 & 3.41 \\
\hline Severe (42 and more) & 29 & 27.37 & 2.90 \\
\hline & \multicolumn{3}{|c|}{$\mathbf{r = 0 . 8 3 9 ;} \mathbf{p}=\mathbf{0 . 0 1}$} \\
\hline
\end{tabular}

Table-5 shows that mother's problem rating score was also found to be significantly correlated with the extent of child's degree of disability $(\mathrm{r}=0.839)$. This high correlation confirms the assumption that greater the problems of the child, more burden the mother will experience in attaining adjustment. Several authors have studied mother's problems; like stress, reactions, coping strategies etc when using different procedures and scales in families of children with disabilities (Rodenburg, Meijer, Dekovic \& Aldenkamp, 2007; Vermaes, Janssens, Mullaart, Vinck, \& Gerris, 2008; Wiegner \& Donders, 2000; Young, Dixon-Woods, Findlay, \& Heney, 2002; Beckman, 1983; Kazak and Clark, 1986). All of them concluded that severity of the handicap was significantly correlated with maternal problems. 


\section{Discussion}

The presence of a child with cerebral palsy in a family disrupts the mother's life in several spheres of activity such as participation in social and household functions, lack of time to look after her personal and health problems, availability of time for the care of other children. All these problems have been grouped together to quantify the problems experienced by the mother of a CP child. The items included in the scale indicated that the researcher was interested only in knowing the perceptions of mothers about the problems presented to them as a result of the presence of a $\mathrm{CP}$ child in the family. Whether the problems faced by them are experienced solely due to the presence of the CP child or not, was looked into.

There is a minimum of social interaction which is essential for the mental health of any individual. The mother of a CP child finds herself burdened with several problems. These include the child's inability to do things him/ her self. Everything has to be done for him/ her self. Elementary needs such as feeding, toilet, bathing, dressing and play require to be looked after, thus severely limiting the time available with the mother even to complete her daily chores, let alone any time for social interaction with friends, relatives and neighbours. As the child grows in size it becomes difficult to carry him if s/he wishes to go out and there is none at home in the nuclear family who would take care of her child. Add to this the insults and humiliations heaped upon her for having produced a defective child, which often lead to tensions between husband and wife and parents in - laws, thus leaving her all alone to face not only the problems of the child but her own as well. If in addition, she has to visit hospital or rehabilitation centres for treatment of the child, the difficulties get multiplied manifold and so do her tensions. Milder the disability, the lesser is the burden placed on the mother and consequently fewer are her problems.

In the present study neither the sex of the child, nor their age or birth orders were found to influence the mother's problem score. The results are consistent with studies reported on problems of mothers of mentally retarded children by Friedrich and Friedrich (1981), Gallager et. al. (1983) and Beckman (1983) who found that child characteristics were not related to problems of the mother.

Less educated mothers obtained significantly low score on mother's problem rating scale indicating poorer adjustment as compared to their educated counterparts. This could be because of educational differences in these two groups. Parents of CP children who had low educational level were also found to have more problems compared to those with higher educational level. Education thus gave the parents the capacity to cope with adversity. This might have been due to better economic means to face difficulties as well as to employ home help for the child as well as domestic chores. Rosenberg (1977) and McCormick (1986) also reported similar results. 
Husband's occupation and family income were also found to be important factors affecting the mother's problems. Women whose husbands had higher occupational prestige and higher income reported less problems compared to those with husbands in low prestige vocation and low income group. These findings are consistent with those reported by Storhaug (1983) and Marshall (1987).

To conclude it can be stated that attitudes of mother play a significant role in determining the problems experienced by mothers. Mothers with positive and favourable attitudes experienced less problems compared to those with unfavourable attitudes. Degree of cerebral palsy, I.Q. level of the child and education of the mother are the three major factors that influence mother's attitude. Age of mother, age and sex of the child and type of family were not found to be related with the attitudes of mothers.

Husband's occupation, education, total number of family members were found to be related with attitude of mother but the relationship of these factors was low (0.23 to 0.39). Mothers having a child with severe degree of cerebral palsy and low IQ score experienced more problems. There was significant correlation between mother's problems rating score and degree of $\mathrm{CP}$ of the child. Parental education, family income and husband's occupation were found to be related with mother's problems but their relationship was low ( 0.23 to 0.32). Age, sex and birth order of the child, mother's own age, and type of family, were not found to have any relationship with the problems experienced.

\section{References}

Beckman, P. J. (1983). Influence of Selected Child Characteristics on Stress in Families of Handicapped Infants. Am. J. Ment. Def. 88: pp, 150-156.

Bhatti, R.S., Channabasavanna, S.M. \& Prabhu, L.R. (1985). A Tool to Study the Attitudes of Parents Towards the Management of Mentally Retarded Children. Child. Psychiat. Quart. 18: pp, 35-43.

Britner, P. A., Morog, M. C., Pianta, R. C., \& Marvin, R. S. (2003). Stress and Coping: A Comparison of Self Report Measures of Functioning in Families of Young Children with Cerebral Palsy or no Medical Diagnosis. Journal of Child and Family Studies, 12, pp, 335-348.

Channabasavanna, S.M., Bhatti, R.S. \& Prabhu, L.R. (1985). A Study of Attitudes of Parents Towards the Management of Mentally Retarded Children. Child Psych \&. Quart. 18: pp, 44-47.

Florian, V. \& Findler, L. (2001). Mental Health and Marital Adaptation among Mothers of Children with Cerebral Palsy. American Journal on Orthopsychiatry, 71, pp, 358-367. 
Friedrich, W . N. \& Friedrich, W .L. (1981). Comparison of Psychosocial Assets of Parents with a Handicapped Child and their Normal Controls. Am. J. of Ment. Def. 85: pp, 551-553.

Gallagher, J.J., Beckman, P. \& Cross, A.H. (1983). Families of Handicapped Children: Sources of Stress and its Amelioration. Except. Children 50: pp, 10-19.

Hummenlinck, A. \& Pollock, K. (2006). Parents' Information Needs about the Treatment of their Chronically Ill Child: A Qualitative Study. Patient Education and Counseling, 62(2), pp, 228-234.

Kazak, A.E. \& Clark, M.W. (1986). Stress in Families of Children with MyelomEningocele. Dev. Med. \& Child. Neurol. 28: pp, 220-228.

King, S., Teplicky, R., King, G. \& Rosenbaum, P. (2004). Family-Centered Service for Children with Cerebral Palsy and their Families: A Review of the Literature. Seminar of Pediatric Neurology, 11, pp, 78-86.

Likert, R.A. (1932). A Technique for the Measurement of Attitudes. Arch. Psychol. 140: pp, $1-55$.

Marshall, T.A. (1987). A Sociological Inquiry Regarding the Effects of Having a Disabled Child in the Family. Dissertation, Abstracts International 47(12) : 4521A.

McCormick, M.C., Charney, E.B. \& Stemmler, M.M. (1986). Assessing the Impact of a Child with Spina biEida on the Family. Dev. Med. \& Child Neurol. 28: pp, 53- 61.

Morris, C. (2009). Measuring Participation in Childhood Disability: How does the Capability Approach Improve our Understanding? Developmental Medicine and Child Neurology, 51, pp, 92-94.

Pain, H. (1999). Coping with a Child with Disabilities from the Parents' Perspective: The Function of Information. Child: Care, Health and Development, 25, pp, 299-312.

Pianta, R. C., Marvin, R. S., Britner, P. A. \& Borowitz, K. C. (1996). Mothers' Resolution of their Children's Diagnosis: Organized Patterns of Caregiving Representations. Infant Mental Health Journal, 17, pp, 239-256.

Raina, P., O’Donnell, M., Rosenbaum, P., Brehaut, J., Walter, S.D., Russell, D., et al. (2005). The Health and Well-Being of Caregivers of Children with Cerebral Palsy. Pediatrics, 115, pp, e626-e636. 
Rodenburg, R., Meijer, A. M., Dekovic, M. \& Aldenkamp, A.P. (2007). Parents of Children with Enduring Epilepsy: Predictors of Parenting Stress and Parenting. Epilepsy Behaviour, 11, pp, 197-207.

Rosenberg, S.A. (1977). Family and Parent Variables Affecting Outcomes of ParentMediated Intervention. Unpublished Doctoral Dissertation. George Peabody College for Teachers.

Seligman, M. (1983). The Family with Handicapped Child Understanding and Treatment, New York. Grune and Stratton, pp. 175-178.

Sensky, T. (1982). Family Stigma in Congenital Physical Handicap. B r . Med. J. 285: 1033-1035.

Storhaug, K. (1983). Aspects of Living Conditions among Groups of Disabled Children and their Families in Norway: Family situations, mother's health, financial assistance. Soc. Sci. Med. 17: pp, 1837-1845.

Verma, I. C. (1989). A Place in the Sun for the Disabled so that they may also Live. A perspective on I.Y.D.P. Indian J. Pediatr. 48: pp, 689-696.

Vermaes, I. P., Janssens, J. M., Mullaart, R. A., Vinck, A. \& Gerris, J. R. (2008). Parents Personality and Parenting Stress in Families of Children with Spina Bifida. Child: Care, Health and Development, 34, pp, 665-674.

Wiegner, S. \& Donders, J. (2000). Predictors of Parental Distress after Congenital Disabilities. Journal of Developmental and Behavioral Pediatrics, 21, pp, 271-277.

Wishart, M.C., Bidder, R.T. \& Gray, O.P. (1981). Parents' Reports of Family Life with Developmentally Delayed Child. Child Care, Health and Develop. 7: pp, 267-279.

Young, B., Dixon-Woods, M., Findlay, M. \& Heney, D. (2002). Parenting in a Crisis: Conceptualizing Mothers of Children with Cancer. Social Science and Medicine, 55, pp, 1835-1847.

Dr. Shaista Naz is Assistant Professor in the Department of Education, Sindh Madressatul Islam University.

Dr. Nasir Sulman is Chairman and Associate Professor in the Department of Special Education, University of Karachi. 